\title{
COMPARING THE EFFECT OF SYSTEMP ON THE ULTRA STRUCTURE AND PERMEABILITY OF ENAMEL FOLLOWING TWO DIFFERENT TECHNIQUES OF ENAMEL ETCHING. AN IN VITRO STUDY
}

\author{
Zeinab A. Salem * and Aboushady, I.M.*
}

\begin{abstract}
Background: Acid etching results in an unintentional demineralization of the enamel surface, while laser conditioning might provide microspaces which then remineralize by trapping free ions; thus enhancing resistance to caries. Since, Systemp desensitizer was very successful in reducing the incidence of post-operative pain; consequently, this in-vitro study was designed to evaluate the effect of Systemp on the surface micro roughness and permeability of enamel following two different techniques of enamel etching; acid and laser etching; in premolar teeth.
\end{abstract}

Methodology: Fifty freshly extracted non-carious premolar teeth were used. The teeth were divided into 5 groups each containing 10 teeth. Group I: control group, group II: teeth exposed to phosphoric acid etching. Group III: teeth exposed to low level laser (LLL) etching. Group IV: Systemp applied to acid etched enamel. Group V: Systemp applied to teeth etched by LLL. The extent of dye penetration was measured using stereo-microscopy and the obtained data were statistically analyzed. The surfaces of the specimens were examined using scanning electron microscopy.

Results: scanning electron microscopic (SEM) examination of group II revealed an obviously porous enamel surface with type III enamel etching pattern. On the other hand, following laser etching, enamel surface showed areas of non removed prismless enamel while most enamel presented type I enamel etching pattern. Systemp application rendered the surface more homogenous especially in the acid etched group. Statistical analysis revealed that the distance travelled by the dye was significantly greater in group II (acid etched group) (mean $\pm \mathrm{SD}=1,406.06 \pm 0.721$ ), than group III (laser etched group) (mean $\pm \mathrm{SD}=1,235.35 \pm 0.771$ ). However, group IV (Systemp applied to acid etched enamel) (mean $\pm \mathrm{SD}=1,078.47 \pm 0.634)$ showed significant reduction than group $\mathrm{V}$ (Systemp applied to LLL etched enaamel) (mean $\pm \mathrm{SD}=1,198.44 \pm 0.583)$ as the p-value was less than 0.05 .

Conclusion and recommendations: despite laser advantages, laser-etching applications should be improved. Besides, desensitizing agents, like Systemp, could be efficient in sealing etched enamel surface, which could reduce sensitivity resulting from leakage through enamel into the underlying dentin.

KEY WORDS: phosphoric acid etching, laser etching, Systemp, dye penetration, SEM.

\footnotetext{
* Lecturer, Oral Biology Department, Faculty of Oral and Dental Medicine, Cairo University.
} 


\section{INTRODUCTION}

Since 1955, when Buonocore introduced phosphoric acid etching for enamel conditioning, the etching methods have changed considerably and new techniques have evolved. Conventionally, 37\% phosphoric acid conditioning for 15 to 60 seconds was the standard procedure with no significant reduction of bond strength ${ }^{(1)}$. However, acid etching results in an accidental demineralization of the enamel surface ${ }^{(2)}$, a permanent loss of about $10 \mu \mathrm{m}$ of the mineralized surface and a possible irritation of the adjacent soft tissues ${ }^{(3)}$.

The use of laser in dentistry was first described at $1964^{(4)}$. The purpose was to modify the enamel surface and increase its resistance against caries ${ }^{(5)}$. A laser conditioned enamel surface has altered calcium to phosphorus and carbonate to phosphorus ratios ${ }^{\left({ }^{6}\right.}$. The percentage of water and organic substances is also reduced (5) which leads to a less acidsoluble enamel surface and hence, caries resistant one ${ }^{(6)}$. Additionally, laser conditioning might provide microspaces which in turn remineralize by trapping free ions which ultimately enhances resistance to caries ${ }^{(5)}$. Surface roughness after laser etching is reported to be similar or lower than with conventional acid etching ${ }^{(7 \& 8)}$.

Systemp desensitizer is a protein precipitate type desensitizer based on the Syntac System. It was very successful clinically and its success rate in reducing the incidence of post-operative pain was exceptionally high ${ }^{(9)}$. Although the exact mechanism of action of desensitizers is still not fully understood, yet, currently used agents probably act by blocking the dentinal tubules through coating, or through coagulation which alters the tubular content, protein precipitation or production of insoluble calcium complexes, or by direct effect on sensory nerves ${ }^{(\mathbf{1 0})}$. According to its manufacturer, the polyethylene glycol dimethacrylate in Systemp desensitizer triggers the precipitation of plasma proteins in the dentinal tubules. On the other hand, glutaraldehyde which is the other component of Systemp desensitizer is a cross linking reagent capable of bonding to amine groups of proteins. It was suggested by that glutaraldehyde is responsible for the occlusion of the tubules due to its effect on the serum proteins in the dentinal fluid as this fixative might precipitate plasma proteins from the dentin tubular liquid through coagulation inside the tubules ${ }^{(11,12)}$.

Consequently, this in-vitro study was designed to evaluate the effect of Systemp on the surface micro roughness and permeability of enamel following two different techniques of enamel etching; acid and laser etching; in premolar teeth.

\section{MATERIALS AND METHODS}

Fifty freshly extracted non-carious premolar teeth were used. The teeth were extracted for orthodontic reasons at the Department of Oral and Maxillofacial Surgery, Faculty of Dentistry, Cairo University. The teeth were stored in saline solution at room temperature until experimental procedures. The teeth were randomly divided into 5 groups each containing 10 teeth: Group I: control group to examine the normal enamel surface, Group II: teeth exposed to phosphoric acid etching, Group III: teeth exposed to low level laser (LLL) etching, Group IV: Systemp applied to phosphoric acid etched teeth and Group V: Systemp applied to LLL etched teeth. The materials, description and application techniques used in this study were listed in table $\mathbf{1 .}$

\section{Methods of Investigation:}

\section{Evaluation of Dye penetration:}

All teeth were embedded in acrylic resin blocks, all crown surfaces were covered with two coats of nail polish except for a cervical window on the buccal surfaces measuring $3 \times 3 \mathrm{~mm}$. Teeth were prepared for dye penetration by extra coverage of crowns and roots by blue inlay wax. Then, the teeth were immersed in methylene blue dye solution 
TABLE (1) Description and application techniques for the materials used in the current study.

\begin{tabular}{|l|l|l|l|}
\hline Material & Type & Description & Application \\
\hline Phosphoric acid & Etching agent & $\begin{array}{l}\text { Meta etchant } \\
37 \% \text { phosphoric acid semi gel } 3 \mathrm{gm}\end{array}$ & Applied by syringe for 30 seconds \\
\hline Low level diode laser & Etching agent & $\begin{array}{l}\text { Wave length } 808 \mathrm{~nm} \\
\text { Power } 0.2 \text { watt }\end{array}$ & Exposure time 2 minutes \\
\hline Systemp & Desensitizing agent & $\begin{array}{l}\text { Polyethylene glycol dimethacrylate } 35.0 \\
\text { Maleic acid }<0.01 \\
\text { Glutaraldehyde }(50 \%) \\
\text { Water } 55.0\end{array}$ & $\begin{array}{l}\text { Thin film spread to the surface } \\
\text { by brushing for } 10 \text { seconds then } \\
\text { dried by air syringe. }\end{array}$ \\
\hline
\end{tabular}

for 24 hours ${ }^{(13)}$. Afterwards, the teeth were rinsed under running tap water and then dried. Finally, they were sectioned buccolingually (Fig. 1 A\&B) into two halves using a low speed saw (Mecatome T201A, Presi, Grenoble, France). All sections were evaluated for dye penetration with a stereomicroscope (Olympus SZ40, Japan) at x200 magnification. The extent of dye penetration was measured from the surface of enamel inwards in an almost horizontal plane (Fig. 1 C).

\section{Scanning electron microscopic examination}

The specimens were left to dry in air at room temperature for 3 days then mounted on scanning electron microscope specimen holder and studied with QUANTAFEG 250 SEM (Field Emission Gun) (with accelerating voltage $30 \mathrm{~K}$.V., magnification $14 \mathrm{x}$ up to 1000000) (FEI company, Netherlands)

\section{Statistical analysis:}

The obtained data from stereo-microscopic images for dye penetration were statistically described in terms of mean \pm standard deviation ( \pm SD) (Table 2). Comparison between the five studied groups was done using one way analysis of variance (ANOVA) test with post hoc multiple 2-group comparisons, $p$ values less than 0.05 were considered statistically significant. All statistical

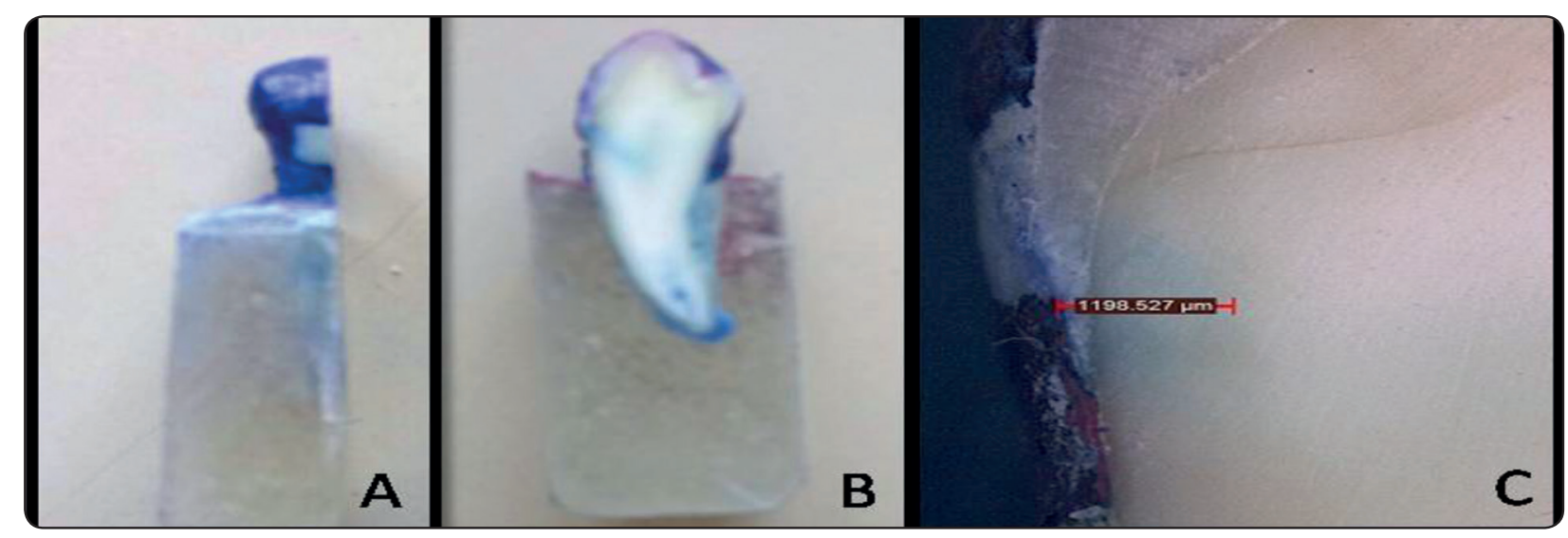

Fig. (1) (A) sectioned tooth in acrylic block covered with blue inlay wax showing buccal window (B) buccolingual sectioning of the tooth for stereo-microscopic imaging (C) A stereo-microscopic image showing the extent of dye penetration through the buccal window (orig. magnification x 200). 
calculations were done using computer program SPSS (Statistical Package for the Social Science; SPSS Inc., Chicago, IL, USA) release 15 for Microsoft Windows (2006).

TABLE (2) Mean \pm standard deviation for the dye penetration results from the five studied groups.

\begin{tabular}{|c|c|c|c|}
\hline Group & Mean & SD & P value* \\
\cline { 1 - 3 } I & $1,044.00$ & 0.672 & \multirow{2}{*}{0.000} \\
\cline { 1 - 2 } II & $1,406.06$ & 0.721 & \\
\cline { 1 - 2 } III & $1,235.35$ & 0.771 & \\
\cline { 1 - 2 } IV & $1,078.47$ & 0.634 & \\
\cline { 1 - 2 } V & $1,198.44$ & 0.583 & \\
\hline
\end{tabular}

* The mean difference is significant at the 0.05 level.

\section{RESULTS}

\section{Dye penetration results:}

The distance penetrated by the dye was maximum in group II (acid etched enamel) (mean $\pm \mathrm{SD}=1,406.06 \pm 0.721)$, followed by group III (LLL etched enamel) (mean $\pm \mathrm{SD}=1,235.35$ \pm 0.771), group V (Systemp applied to LLL etched enamel) (mean $\pm \mathrm{SD}=1,198.44 \pm 0.583)$, group IV (Systemp applied to acid etched enamel) (mean $\pm \mathrm{SD}=1,078.47 \pm 0.634$ ) and was least in group I (unetched enamel) (mean $\pm \mathrm{SD}=1,044.00 \pm 0.672)$.

\section{Scanning electron microscopic (SEM) results:}

\section{Group I:}

Examination of the normal enamel surface revealed a generally smooth surface with series of transverse wave-like depressions (perikymata) and circular pits corresponding to the Tomes' processes of ameloblasts (Figs. 2 A\&B).

\section{Group II:}

Scanning electron microscopic examination of the acid-etched enamel surface revealed an obviously porous enamel surface which presented type III enamel etching pattern (mixed etching pattern). Areas of preferential removal of prisms and interprismatic regions could be noticed (Figs. $3 \mathrm{~A} \& \mathrm{~B})$.

\section{Group III:}

When the enamel surface was examined by scanning electron microscope after laser application, it showed some areas of prismless enamel which were not removed (fig. 4A) while most enamel presented type I enamel etching pattern with

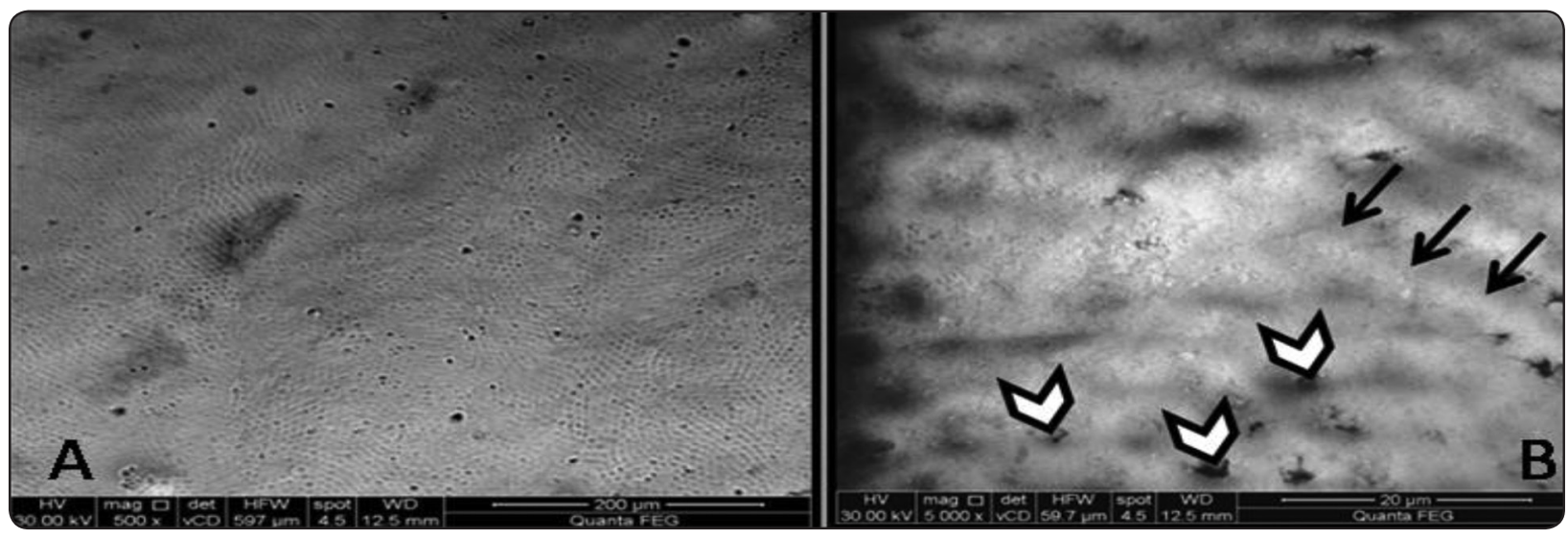

Fig. (2) Scanning electron micrograph of normal enamel surface showing: A) a generally smooth enamel surface with small circular pits, B) a higher magnification showing transverse wave-like depressions (perikymata) (arrows) and circular pits corresponding to the Tomes' processes of ameloblasts (arrow heads) (Original magnification: A-500X \&B-5000X). 
preferential removal of enamel prisms (Fig. 4B). Occasionally, surface cracks were seen on enamel (Fig. 4A).

\section{Group IV:}

In this group, following Systemp application on acid etched enamel, obscured enamel prisms and inter-prismatic areas were evident. Homogeneous, thin and smooth enamel surface deposits were apparent. Isolated pitted areas and fine cracks were also observed (Figs. 5 A\&B).

\section{Group V:}

Examinatiom of this group showed that the application of Systemp on laser etched enamel appeared to seal the enamel prism as the fish scales pattern of the enamel preims was apparent. Surface deposits in the form of furrows intermingeled with uncovered prismless enamel were seen. Few pitted areas were also observed. However, other areas reflected homogeous covering of the etched enamel surface (Figs. 6A\&B).

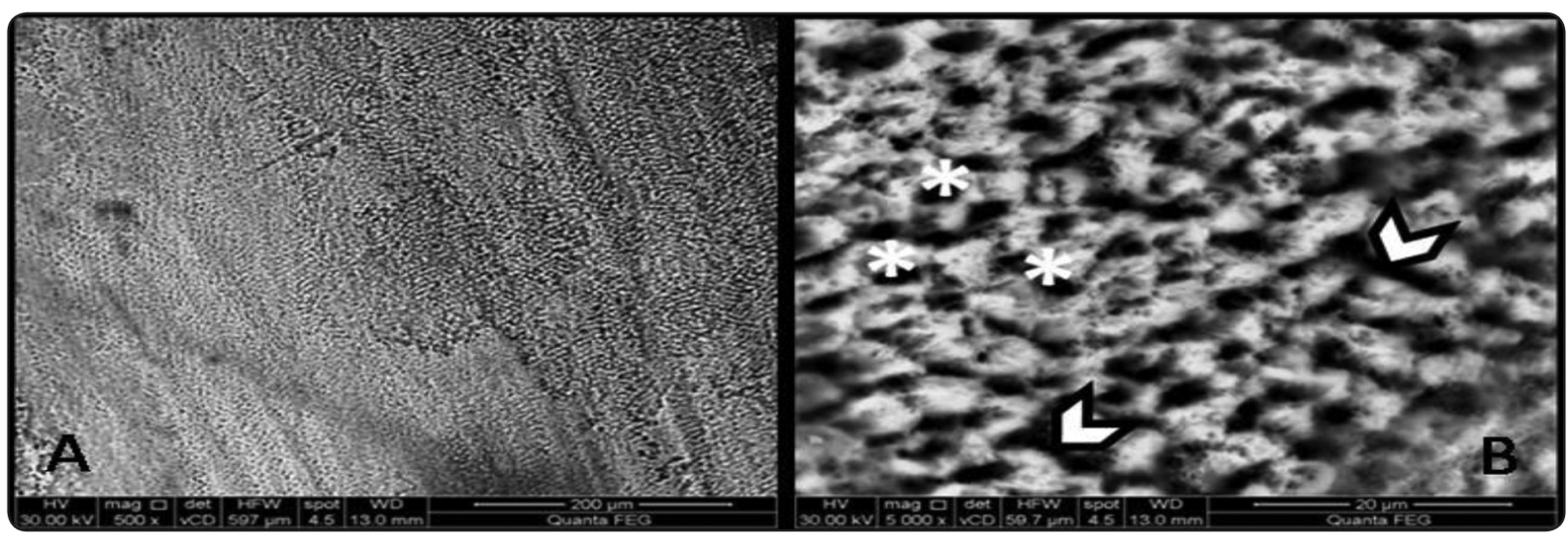

Figure (3) Scanning electron micrograph of enamel surface etched with 37\% phosphoric acid for 30 sec. showing: A) a highly porous enamel surface, B) a higher magnification showing type III enamel etching pattern with alternating areas of preferential removal of prisms (asterix) and interprismatic regions (arrow heads) (Original magnification: A-500X \&B-5000X).

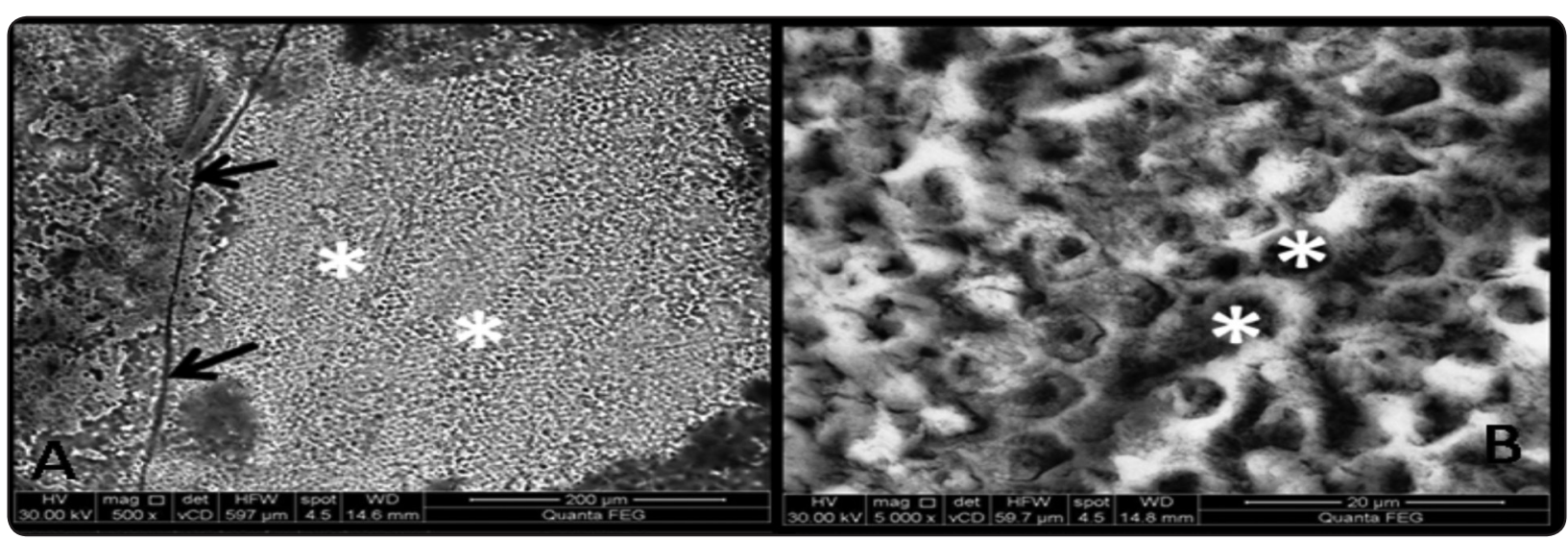

Fig. (4) Scanning electron micrograph of laser etched enamel surface showing: A) the presence of a roughened enamel surface, some areas of prismless enamel were not removed (asterix) and surface cracks were occasionally seen (arrows), B) a higher magnification showing type I enamel etching pattern with preferential removal of enamel prisms (asterix) (Original magnification: A-500X \&B-5000X). 


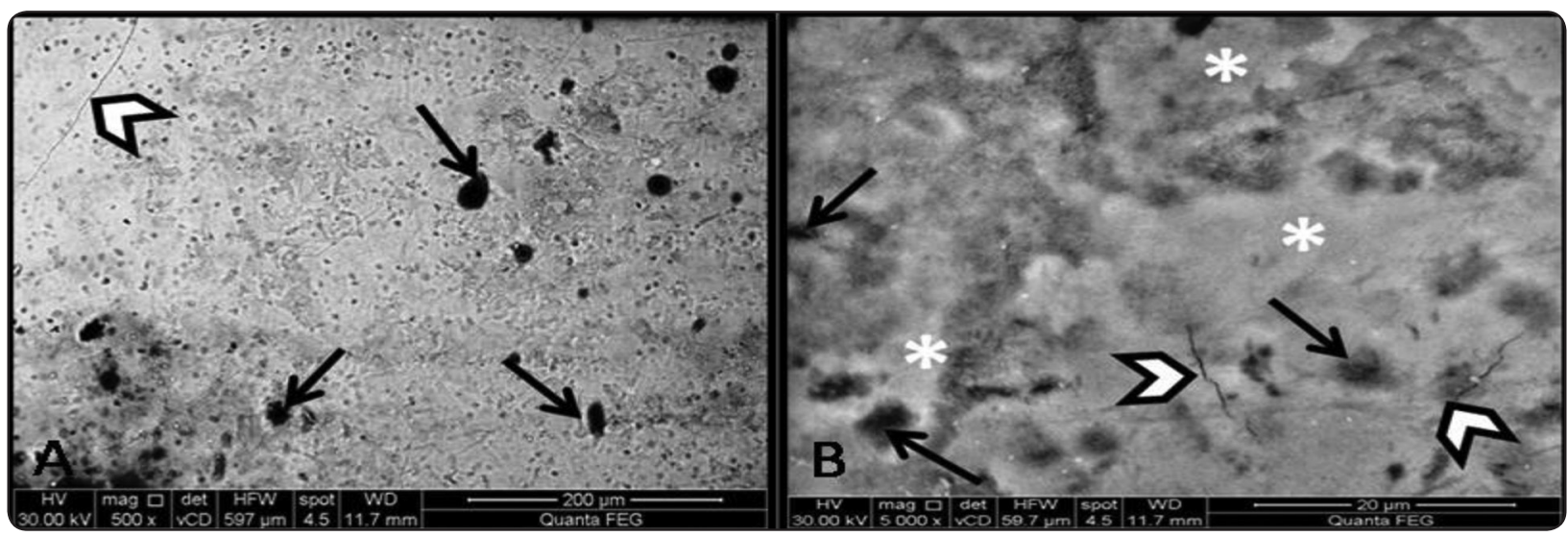

Fig. (5) Scanning electron micrograph of acid etched enamel surface after Systemp application showing: A) areas of smooth thin deposits and few pits (arrows), also fine cracks were observed (arrow heads), B) a higher magnification showing the smooth thin deposits on enamel (asterix), scattered pits (arrows) and fine cracks (arrow heads) (Original magnification: A-500X \&B-5000X).

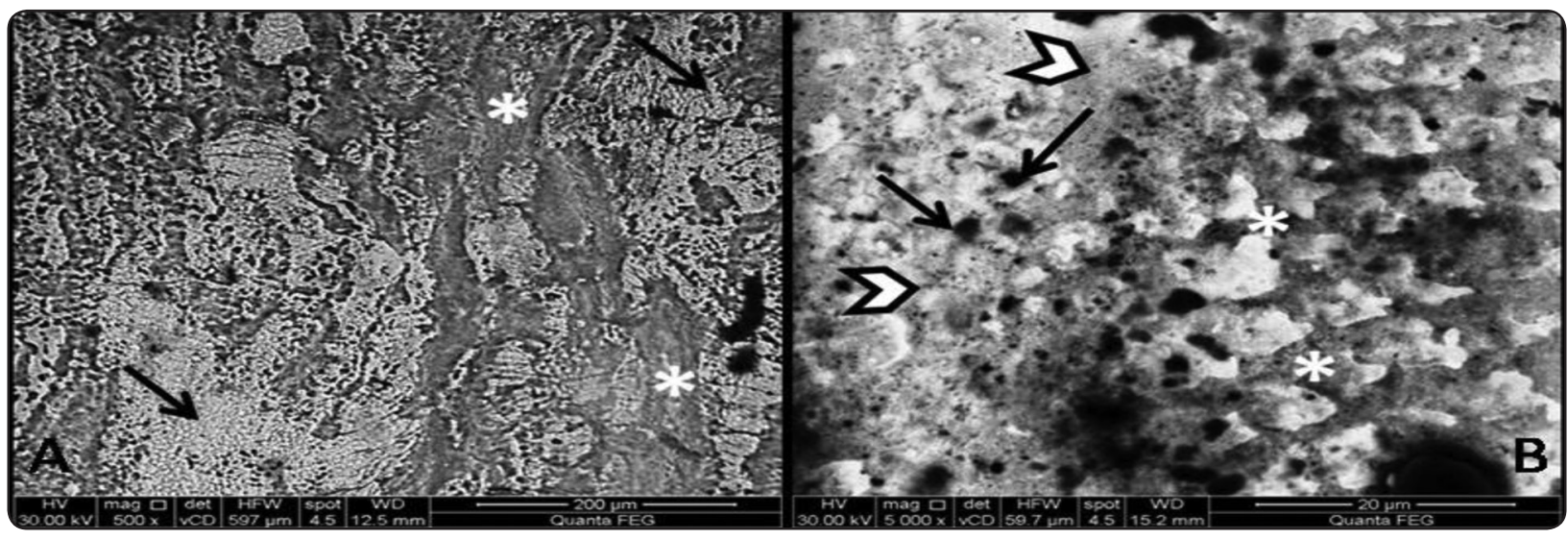

Fig. (6) An electron micrograph of laser etched enamel surface following Systemp application showing: (A) surface deposits in the form of furrows (asterix) intermingeled with uncovered prismless enamel (arrows). (B) a higher magnification showing sealed inter prismatic areas with apparent fish scales pattern of the prisms (asterix), homogeous covering of the etched enamel surface in isolated areas (arrow heads) and few pits were also noticed (arrows).

\section{DISCUSSION}

Phosphoric acid is one of the best techniques to bond resins to enamel. The smear layer is removed by acid application on the enamel surface. Microscopic roughness and enamel surface energy are improved by removing prismatic and interprismatic crystals. In general, 10-37\% orthophosphoric acid is applied to both enamel and dentin ${ }^{(14)}$. Acid etching using a $35 \%$ orthophosphoric acid gel resulted in the greatest shear bond strength ${ }^{(15)}$. However, acid etching causes chemical changes that can alter the organic substance and decalcify the inorganic constituent.
As a consequence of this demineralization, enamel becomes more prone to caries ${ }^{(\mathbf{1 6}, \mathbf{1 7})}$.

The literature contains conflicting findings concerning surface treatments and cavity preparations with lasers. For cutting enamel, highirradiation outputs are used varying from 2.5 to 6 $\mathrm{W}$. The lasers used for the treatment of sensitive teeth may be divided into two groups: a) the middle output power lasers - neodymium-doped yttrium aluminium garnet (Nd:YAG) and $\mathrm{CO} 2$ lasers and b) the low-level lasers-helium-neon ( $\mathrm{He}-\mathrm{Ne})$ and gallium-aluminum-arsenide (GaAlAs) (diode) 
lasers. The low-level or 'soft' lasers provide cold thermal low energy wavelengths with slight temperature increase of $<0.1{ }^{\circ} \mathrm{C}$. These wavelengths are assumed to stimulate circulation, cellular action and to provide various effects such as antiinflammatory, vascular, analgesic and tissue healing effects ${ }^{(18)}$. Additionally, numerous researches have demonstrated the effect of low-level lasers on dentinal hypersensitivity and most studies have used GaAlAs laser therapy ${ }^{(\mathbf{1 9} 20)}$. Moreover, in 2011, a lower output $2 \mathrm{~W}$ erbium was used, chromium: yattrium-scandium-gallium-garnet (Er, Cr: YSGG) laser to etch the enamel ${ }^{(21)}$.

At present, laser etching of enamel surfaces is well known because of the potential drawbacks of acid etching. Laser etching could be a substitute to acid etching of enamel and dentin. Of the wellknown advantages of laser etching is the production of acid-resistant surfaces ${ }^{(22)}$.

It is well recognized that physicochemical changes occurring after laser etching made the tooth more resistant to caries. It was reported that remineralization places acting like free-ion traps occurred with laser etching ${ }^{(5)}$. In addition, caries reduction was linked to the altered calcium-tophosphorous ratio, leading to reduction of carbonate and pyrophosphate formation (23). Additionally, through SEM examination it was observed that Er, Cr: YSGG laser irradiation produced etching patterns similar to those of acid etching ${ }^{(24)}$.

In the present work, SEM examination of the acid-etched enamel surface (group II) revealed an obviously porous enamel surface which presented type III enamel etching pattern with alternating areas of preferential removal of prisms and interprismatic regions. On the other hand, following laser etching, enamel surface showed some areas of non-removed prismless enamel while most enamel presented type I enamel etching pattern with preferential removal of enamel prisms.

Regarding the dye penetration results in the current investigation, statistical analysis revealed that the distance penetrated by the dye was noticed to be significantly greater in the acid etched group (mean $\pm \mathrm{SD}=1,406.06 \pm 0.721$ ), when compared to the laser etched group (mean $\pm \mathrm{SD}=1,235.35 \pm 0.771)$, as the $\mathrm{p}$-value was less than 0.05 . This, in turn, implies that acid etching was more effective in creating surface roughness than laser etching.

Findings regarding utilizing lasers for enamel etching are conflicting. For example, in 2009, the microtensile bond strength was investigated between enamel and two bonding agents. It was found that the microtensile bond strength was significantly lower in the acid-etched group than the $\mathrm{Er}, \mathrm{Cr}$ : YSGG and Nd: YAG laser-etched enamel groups for both bonding agents ${ }^{(25)}$. On the other hand, some researchers stated that laser irradiation was not capable of etching enamel. Other investigation found weaker bond forces in an Er: YAG laseretched enamel surface than in an acid etched enamel surface. This was associated with sub-surface cracks observed in SEM images ${ }^{(23)}$. Additionally, another study declared that Er, Cr: YSGG laser-etching techniques were not a sufficient way to improve the bond between enamel and stainless steel orthodontic brackets when compared to acid-etching techniques (26). Furthermore it was confirmed that Er: YAG laser irradiation didn't eliminate the need to etch the enamel surface with acid before applying sealants. These results are in agreement with the outcomes obtained in the present study ${ }^{(27 \& 28)}$.

Clinician's skill to bond a restoration to enamel has subjective changes in prosthetic and cavity preparations, restorative advances for esthetic improvements, bonding techniques for orthodontic devices and the treatment of caries ${ }^{(29,30 \& 31)}$. Bonding to enamel has been historically studied for over 50 years and hard work has been made to create a simplified alternative, however; acid etching of enamel remained the most effective method for steady enamel bonding (32). Additionally, bleaching treatment is highly praised by patients, and it is a wellknown procedure in most esthetic dental treatments. In spite of possessing good esthetic effects; 
tooth whitening has some drawbacks including: tooth sensitivity ${ }^{(33-36)}$ and structural changes such as reduction of enamel microhardness ${ }^{(37 \& 38)}$ and increased surface roughness ${ }^{(39,40)}$. Based on the mentioned facts, the current study was performed in order to explore the effect of Systemp; one of the most commonly used desensitizing agents; on enamel microstructure, enamel surface roughness and enamel permeability following enamel etching either by phosphoric acid or by low level laser.

Concerning the SEM results obtained in the present work, they revealed that Systemp had the ability to change the surface morphology of enamel following etching either by phosphoric acid or LLL. Systemp application rendered the surface more homogenous in texture as a result of sealing the opened prism and/ or the inter-prismatic regions. In addition, the dye penetration results showed that the distance penetrated by the dye was least among groups IV\&V where Systemp was applied following acid and laser etching respectively. Furthermore, statistical results have confirmed that the dye penetration in group IV (Systemp applied to acid etched enamel $)($ mean $\pm S D=1,078.47 \pm 0.634)$ was significantly reduced than that in group $\mathrm{V}$ (Systemp applied to laser etched enamel) (mean $\pm \mathrm{SD}=1,198.44 \pm 0.583)$ as the $\mathrm{p}$-value was less than 0.05 .

Numerous former studies were performed on Systemp as a dentine desensitizer; these studies demonstrated that Systemp desensitizer was valuable in reducing pain resulting from dentine hypersensitivity. These results remain unchanged whether or not the tooth was acid-etched prior to application of the desensitizing agent ${ }^{(41)}$.

Since Systemp desensitizer is often used in conjunction with other temporary and permanent dental restoratives, it is applied after etching to increase the bond strength. This reaction may be attributed to the fact that glutaraldehyde is capable of fixing the smear layer of prepared dentin ${ }^{(42)}$. As a part of Systemp, polyethylene glycol dimethacrylate is a main constituent of different resin based restorative materials ${ }^{(43,44)}$.

Furthermore, an immunoblotting studyeas done and the authors demonstrated that enamel proteins reacted with the anti-vimentin antibody after fixation with glutaraldehyde. They suggested that the observed immunoreaction is directed against an epitope apparently created by cross linking of enamel proteins during fixation with glutaraldehyde ${ }^{(45)}$. This finding support our results regarding the glutaraldehyde content in the Systemp which was capable of cross linking the enamel proteins, thus reducing the permeability of enamel in group IV and $\mathrm{V}$ as revealed by the dye penetration results.

Conclusively, despite laser advantages and because of the low bond strength reported in many studies $^{(25,28)}$, laser-etching applications should be improved. Besides, desensitizing agents, like Systemp, could be beneficial in efficient sealing of etched enamel surface, which could improve microleakage around restorations involving enamel, and in turn, could reduce sensitivity which may result from leakage through enamel into the underlying dentin.

\section{REFERENCES}

1. Brännström M and Nordenvall KJ (1977) The effect of acid etching on enamel, dentine and the inner surface of the resin restoration. J Dent Res 56: 917-923.

2. Boyd RL (1993) Comparison of three self-applied topical fluoride preparations for control of decalcification. Angle Orthod 63: 25-30.

3. Gange P (1995) Present state of bonding. J ClinOrthod 7: $429-436$

4. Stern RH and Sognnaes RF (1964) Laser beam effect on dental hard tissues. J Dent Res 43: 873

5. Oho T and Morioka T (1990) A possible mechanism of acquired acid resistance of human dental enamel by laser irradiation. Caries Res T 24: 86-92.

6. Keller U and Hibst R (1990) Ultrastructural changes of enamel and dentine following Er:YAG laser radiation on teeth. Proc SPIE 1200: 408-415. 
7. Hess JA (1990) Scanning electron microscopic study of laser-induced morphologic changes of a coated enamel surface. Lasers Surg Med 10: 458- 462.

8. Arcoria CJ, Lippas MG, Vitasek BA (1993) Enamel surface roughness analysis after laser ablation and acid etching. $\mathrm{J}$ Oral Rehabil 20: 213-224.

9. Cox CF and O’Neal SJ (1994). Biologic and clinical evaluation of Syntac and Variolink systems for cohesive pretreatment of hypersensitivity and definitive cementation. Signature, Winter 3-7.

10. Addy M. (2002) Dentine hypersensitivity: New perspectives on an old problem. Int Dent J; 52:367-75.

11. Duran I, Sengun A, Yildirim T and Ozturk B. (2005) In vitro dentine permeability evaluation of HEMA-based (desensitizing) products using split-chamber model following in vivo application in the dog. J Oral Rehabil $32: 34-8$.

12. Ishihata $H$, Finger WJ, Kanehira M, Shimauchi $H$ and Komatsu M. (2011) In vitro dentin permeability after application of Gluma ${ }^{\circledR}$ desensitizer as aqueous solution or aqueous fumed silica dispersion. J Appl Oral Sci; 19:147-53.

13. Souza EM, Pappen FG, Shemesh H, Bonanato-Estrela C and Bonetti-Filho L. (2009) Reliability of assessing dye penetration along root canal fillings using methylene blue. Aust Endod J 35 (3): 158-63.

14. Waggoner WF and Siegal M (1996) Pit and fissure sealant application: updating the technique. J Am Dent Assoc 127: 351-361.

15. Lin S, Caputo AA, Eversole LR and Rizoiu I (1999) Topographical characteristics and shear bond strength of tooth surfaces cut with a laser-powered hydrokinetic system. J Prosthet Dent 82: 451-455.

16. Cehreli SB, Gungor HC and Karabulut E (2006) Er, Cr: YSGG laser pretreatment of primary teeth for bonded fissure sealant application: a quantitative microleakage study. J Adhes Dent 8: 381-386.

17. Sungurtekin E and Oztas N (2010) The effect of erbium, chromium: yttriumscandium- gallium-garnet laser etching on marginal integrity of a resin-based fissure sealant in primary teeth. Lasers Med Sci 25: 841-847.

18. Gerschman, J.A., Ruben, J. and Gebart-Eaglemont, J. (1994) Low level laser therapy for dentinal tooth hypersensitivity. Australian Dental Journal 39, 353.
19. Coleton, S. (1998) Sensitivity and laser treatment. J Am Dent Assoc. 129(9):1200, 1204.

20. Kimura, Y., Wilder-Smith, P., Yonaga, K. and Matsumoto, K. (2000) Treatment of dentine hypersensitivity by lasers: a review. J Clin Periodontol. 27(10):715-21.

21. Baygin O., Korkmaz F. M., Tuzuner T. and Tanriver M. (2011) The Effect of Different Techniques of Enamel Etching on the Shear Bond Strengths of Fissure Sealants. Dentistry 1:3

22. Visuri SR, Gilbert JL, Wright DD, Wigdor HA and Walsh JT Jr (1996) Shear strength of composite bonded to Er: YAG laser-prepared dentin. J Dent Res 75: 599-605.

23. Martínez-Insua A, Da Silva Dominguez L, Rivera FG and Santana-Penín UA (2000) Differences in bonding to acid-etched or Er: YAG-laser-treated enamel and dentin surfaces. J Prosthet Dent 84: 280-288.

24. Berk N, Basaran G and Ozer T (2008) Comparison of sandblasting, laser irradiation, and conventional acid etching for orthodontic bonding of molar tubes. Eur $\mathrm{J}$ Orthod 30: 183-189.

25. Tarçin B, Günday M, Oveçoğlu HS, Türkmen C, Oveçoğlu ML, Oksüz M and Ay M. (2009) Tensile bond strength of dentin adhesives on acid- and laser-etched dentin surfaces. Quintessence Int. 40(10):865-74.

26. Uşümez S, Orhan M and Uşümez A. (2002) Laser etching of enamel for direct bonding with an Er, Cr: YSGG hydrokinetic laser system. Am J Orthod Dentofacial Orthop. 122(6):649-56.

27. Borsatto MC, Corona SA, Ramos RP, Liporaci JL, Pécora JD and Palma-Dibb RG. (2004) Microleakage at sealant/enamel interface of primary teeth: effect of Er: YAG laser ablation of pits and fissures. J Dent Child (Chic) 71: 143-147.

28. Lupi-Pégurier L, Bertrand MF, Genovese O, Rocca JP and Muller-Bolla M (2007) Microleakage of resin-based sealants after Er: YAG laser conditioning. Lasers Med Sci 22: $183-188$.

29. Perdigão J and Lopes M. (1999a) Dentin bonding - state of the art. Compend Contin Educ Dent. 20:1151-1162.

30. Perdigão J and Lopes M. (1999b) Dentin bonding-questions for the new millennium. J Adhes Dent. 1:191-209.

31. Lopes GC, Baratieri LN, de Andrada MA and Vieira LC. (2002) Dental adhesion: present state of the art and future perspectives. Quintessence Int. 33(3):213-24. 
32. Lopes GC , Thys G D, Klauss P, Mussi G and Widmer N (2007) Enamel Acid Etching: A Review. Compendium. 28: 662-669

33. Goldberg M, Grootveld M and Lynch E. (2010) Undesirable and adverse effects of tooth-whitening products: A review. Clin Oral Investig 14:1-10.

34. FDI World Dental Federation. (2013). Mexico City, Mexico: 2011. FDI policy statement on dental bleaching materials: adopted bythe FDI General Assembly : 17 September 2011 - Mexico City, Mexico. Int Dent J. 63(1):2-3. doi: 10.1111/idj.12013. Epub 2013 Feb 5.

35. Basting RT, Amaral FL, França FM and Flório FM. (2012) Clinical comparative study of the effectiveness of and tooth sensitivity to $10 \%$ and $20 \%$ carbamide peroxide home-use and $35 \%$ and $38 \%$ hydrogen peroxide in-office bleaching materials containing desensitizing agents. Oper Dent.;37:464-73.

36. Özcan M, Abdin S and Sipahi C. (2014) Bleaching induced tooth sensitivity: Do the existing enamel craze lines increase sensitivity? A clinical study. Odontology. 102:197-202.

37. Borges AB, Yui KC, D’Avila TC, Takahashi CL, Torres CR and Borges AL. (2010) Influence of remineralizing gels on bleached enamel microhardness in different time intervals. Oper Dent.;35:180-6.

38. Zanet CG, Fava M and Alves LA. (2011) In vitro evaluation of the microhardness of bovine enamel exposed to acid solutions after bleaching. Braz Oral Res. 25:562-7.

39. Azrak B, Callaway A, Kurth P and Willershausen B. (2010) Influence of bleaching agents on surface roughness of sound or eroded dental enamel specimens. J Esthet Restor Dent. 22:391-9.

40. Sa Y, Sun L, Wang Z, Ma X, Liang S, Xing W, Jiang T and Wang Y. (2013) Effects of two in-office bleaching agents with different $\mathrm{pH}$ on the structure of human enamel: An in situ and in vitro study. Oper Dent 38:100-10.

41. Stewardson DA, Crisp RJ, McHugh S, Lendenmann U and Burke FJ. (2004) The Effectiveness of Systemp. desensitizer in the treatment of dentine hypersensitivity. Prim Dent Care.;11:71-6.

42. Dijkman GEHM, Jongebloed WL, de Vries J, Ögaard B and Arends J (1994). Closing of dentinal tubules by glutardialdehyde treatment, a scanning electron microscopy study. Scand. J. Dent. Res. 102:144-150.

43. Guigui W. (1998) Perfluorotriethylene glycol dimethacrylate modified composite resins for improved dental restoratives-Dental resins publisher Ohio State University, ProQuest Dissertations And Theses; Thesis (Ph.D.)--The Ohio State University, Publication Number: AAI9900927; ISBN: 9780591978339; Source: Dissertation Abstracts International, Volume: 59-08, Section: B, pp: 4399.; 137 .

44. Joon-Yong S.; Jong Su I.; Sung-Jin G.; Jae-ak C.; Junhwa S. and Young-Chang N. (2009) Preparation and characterization of a PVDF-HFP/PEGDMA-coated PE separator for lithium-ion polymer battery by electron beam irradiation. Radiation Physics and Chemistry, 78: 505-508.

45. Josephsen K, Smith CE and Nanci A. (1999) Selective but nonspecific immunolabeling of enamel protein-associated compartments by a monoclonal antibody against vimentin. J Histochem Cytochem 47:1237-1245. 